
\title{
CS Research Square \\ Management of Pancreatic Trauma in Urban India: A Multicenter Study
}

\section{Devi Bavishi}

The University of Texas Health Science Center at Houston

\section{Monty Khajanchi}

King Edward Memorial Hospital and Seth G.S. Medical College

\section{Ramlal Prajapati}

King Edward Memorial Hospital and Seth G.S. Medical College

Anita Gadgil

Bhabha Atomic Research Center Hospital

\section{Bhakti Sarang}

Terna Medical College and Hospital

\section{Kapil Dev Soni}

JPN Apex Trauma Centre, AlIMS

\section{Amay Banker}

King Edward Memorial Hospital and Seth G.S. Medical College

\section{Dhanashree Moghe}

King Edward Memorial Hospital and Seth G.S. Medical College

Martin Gerdin Wärnberg ( $\square$ martin.gerdin@ki.se )

Karolinska Institutet

\section{Research Article}

Keywords: abdominal injuries, pancreas

Posted Date: November 1st, 2021

DOI: https://doi.org/10.21203/rs.3.rs-992460/v1

License: (c) (i) This work is licensed under a Creative Commons Attribution 4.0 International License. Read Full License 


\section{Abstract}

\section{Background}

Pancreatic trauma occurs in $0.2-2 \%$ of patients with blunt trauma and $1-12 \%$ of patients with penetrating trauma. The mortality and morbidity rates range from $9-34 \%$ and $30-60 \%$ respectively. We aimed to review the management of pancreatic trauma in a multicenter database from India.

\section{Methods}

We analyzed all patients who suffered a pancreatic injury and who were included in the multicenter prospective observational study 'Towards Improved Trauma Care Outcomes (TITCO)'.

\section{Results}

Of the 16047 trauma cases, 1134 (7.1\%) patients suffered abdominal trauma. Of all those with abdominal trauma 55 patients $(4.9 \%)$ had injury to the pancreas. 28 patients $(50.9 \%)$ with pancreatic trauma were managed conservatively. 27 patients $(49.1 \%)$ underwent surgical exploration in the form of laparotomies. 11 procedures were undertaken for pancreas. A total of $45(82 \%)$ patients had associated injuries along with pancreatic injury. Thorax (19) (including injuries to lung, pleura and ribs), liver (17), bowel (14) and spleen (13) were the most common associated injuries.

\section{Conclusion}

Conservative management was as common as operative management in patients with pancreatic injuries. Most $(80 \%)$ grade III/IV underwent operative treatment. Many patients (82\%) had associated injuries.

\section{Level of evidence: III}

\section{Background}

In patients with polytrauma, abdominal trauma is common with an incidence of $7-10 \%(1,2)$. The incidence of pancreatic injury in abdominal trauma is $3-12 \%$ (3). In a population-based study of 52,000 trauma patients in Scotland, the incidence of pancreatic injuries was $0.2 \%$ (4). Pancreatic trauma occurs in $0.2-2 \%$ of patients with blunt trauma and $1-12 \%$ of patients with penetrating trauma (5). The mortality and morbidity rates range from $9-34 \%$ and $30-60 \%$ respectively(6).

The retroperitoneal location of pancreas partly explains the low incidence of pancreatic trauma in abdominal injuries. Its location also means that pancreatic injury is a marker of severe trauma. The pancreas' association with surrounding visceral and vascular injuries may lead to concomitant injuries and significant morbidity - including pancreatic fistula, pseudocyst, pancreatitis, repeated surgeries (7), and mortality (8).

The overall management depends on the associated injuries and the status of the main pancreatic duct (6). There are single center studies (9-14) from India and China that highlight the demographics and management of pancreatic trauma patients, but no multicenter studies from low-middle income countries(4). We therefore aimed to review the management of pancreatic trauma in a multicenter database from India.

\section{Methods}




\section{Study design}

We analyzed all patients who suffered a pancreatic injury and who were included in the multicenter prospective observational study 'Towards Improved Trauma Care Outcomes (TITCO)' in India conducted from October 2013 to December 2015 (15).

\section{Setting}

The study was conducted in four public university hospitals in India. These urban referral tertiary care hospitals are situated in Kolkata, Mumbai (2-centers) and Delhi, cities with populations of more than 10 million. The hospitals were King Edward Memorial Hospital (KEMH) and Lokmanya Tilak Municipal General Hospital (LTMGH) in Mumbai, Jai Prakash Narayan Apex Trauma Centre (JPNATC) in New Delhi and the Institute of Post-Graduate Medical Education and Research and Seth Sukhlal Karnani Memorial Hospital (SSKM) in Kolkata. Each of these hospitals receive around 20 to 30 major trauma patients per week. They have 24-hour emergency services, imaging, operating theatres and sub-specialty available.

\section{Data Collection}

One dedicated project officer per hospital collected the data. They collected data by directly observing care for patients admitted during their shifts and by extracting data from hospital records for patients admitted outside their shifts. Patients were followed up until discharge or death, whichever occurred first over a 30-day period. Certified coders calculated the Injury Severity Score (ISS) of each patient based on injury descriptors extracted from patient records, including imaging reports and surgical notes.

\section{Participants}

TITCO included all patients with life or limb threatening injuries admitted to the participating hospitals. For this analysis, patients with pancreatic injury corresponding to the International Classification of Diseases (ICD) 10 code S36.2 were extracted from the TITCO database.

\section{Variables}

Demographic variables analysed were age, sex, mechanism of injury, mode of transport, and type of injury (blunt or penetrating). Clinical profile was analysed in terms of vital signs, imaging, intervention, length of stay and final outcome (death/discharge). Pancreatic injuries were graded according to the Organ Injury Scale (OIS) developed by the American Association for the Surgery of Trauma (AAST) from Computed Tomography (CT) findings and operative data(16). Data were not sufficient to differentiate grade I from II, hence they were combined as I/II. Data were not available for 4 patients and 17 patients could not be classified due to incomplete records and were coded as data not available. Length of stay and in-hospital mortality were entered.

\section{Analyses}


Means with standard deviations were calculated for continuous variables, and medians with interquartile range were calculated for non-normal continuous variables. Categorical variables are presented as counts and proportions.

\section{Results}

Of the 16047 trauma cases, 1134 (7.1\%) patients suffered abdominal trauma. Of all those with abdominal trauma 55 patients $(4.9 \%)$ had injury to the pancreas. The mean age of these 55 patients with pancreatic injury was $27(S D=13)$ years, $50(91 \%)$ were males, and 51 (93\%) suffered blunt trauma. The main mechanism of injury was road traffic injury $(32,58 \%)$ followed by falls $(14,25.5 \%)$. More than two thirds $(37,67 \%)$ of the patients were transferred to the participating centers. Most came to the participating centers via ambulance (38,69\%). Out of the 55 patients 13 died in hospital within 30 days (24\%). (Table 1 )

\section{Table 1}

\section{Demographics, Physiology and Outcomes of patients with Pancreatic trauma}




\begin{tabular}{|c|c|c|}
\hline Variables & Patients $\mathrm{n}=55$ & Missing values (n) \\
\hline Age in years, mean (SD) & $27(13)$ & 0 \\
\hline Male sex, n (\%) & $50(90.9)$ & 0 \\
\hline Mode of injury, $n(\%)$ & & 0 \\
\hline - Blunt & $51(92.7)$ & \\
\hline - Penetrating & $4(7.3)$ & \\
\hline Mechanism of injury, n (\%) & & 0 \\
\hline - $\quad$ Road traffic injury & $32(58.2)$ & \\
\hline - Fall & $14(25.5)$ & \\
\hline - Railway & $2(3.6)$ & \\
\hline - $\quad$ Assault & $4(7.3)$ & \\
\hline - $\quad$ Other & $3(5.5)$ & \\
\hline Transferred, n (\%) & $37(67)$ & 0 \\
\hline Mode of transport, $n(\%)$ & & 0 \\
\hline - $\quad$ Ambulance & $38(69)$ & \\
\hline - $\quad$ Police & $4(7)$ & \\
\hline - $\quad$ Private car & $9(16)$ & \\
\hline - $\quad$ Taxi & $4(7)$ & \\
\hline SBP in mmHg, median (IQR) & $120(110-128)$ & 3 \\
\hline $\mathrm{HR}$ as beats per min, median (IQR) & $88(80-110)$ & 0 \\
\hline RR per min, median (IQR) & $18(16-20)$ & 3 \\
\hline Hemoglobin in g/dl, median (IQR) & $12.5(11.8-13.3)$ & 6 \\
\hline ISS score, median (IQR) & $14(9-22)$ & 12 \\
\hline - $\quad$ Mild (<9), n (\%) & $8(14.6)$ & \\
\hline - $\quad$ Moderate (9-15), n (\%) & $14(25.4)$ & \\
\hline - $\quad$ Severe (16-25), n (\%) & $16(29.1)$ & \\
\hline Profound (>25), n (\%) & $5(9.1)$ & \\
\hline - $\quad$ Missing, $\mathrm{n}(\%)$ & $12(21.8)$ & \\
\hline Mortality, n (\%) & $13(23.6)$ & \\
\hline \multicolumn{3}{|c|}{$\begin{array}{l}\mathrm{SBP} \text { - systolic blood pressure, HR - heart rate, RR - respiratory rate, , ISS - Injury severity score. Continuous } \\
\text { variables are represented by median in parentheses by IQR }\end{array}$} \\
\hline
\end{tabular}


A total of $45(82 \%)$ patients had associated injuries along with pancreatic injury. Thorax (including injuries to lung, pleura and ribs), liver, spleen and bowel were the most common associated injuries (Figure 1).

\section{Diagnostic modalities}

Out of 55 patients, Focused Assessment with Sonography for Trauma (FAST) was done in 52 patients (94.5\%). Out of three patients in whom FAST was not done two underwent exploratory laparotomy immediately. A total of 47 (85\%) patients underwent CT imaging. Four (7\%) patients underwent exploratory laparotomy without the CT scan. The remaining four patients did not undergo CT nor laparotomy and their details and reasons were not available.

\section{Pancreatic trauma grading}

19 patients (34.5\%) had grade I/II pancreatic injury, 10 patients had grade III injury, four patients had grade IV injury and only one patient had grade $\mathrm{V}$ pancreatic injury (Table 2).

\begin{tabular}{|c|c|c|c|c|c|c|c|}
\hline & & & Table & 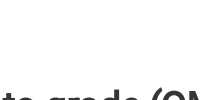 & 2. & (amp & \\
\hline & Managemen & of pancreatic in & ries accordin & to grade (ON & operative man & gement) & \\
\hline & Conservative & Operative & & & & Combined & $\begin{array}{l}\text { Length } \\
\text { of stay } \\
\text { (days in } \\
\text { median) }\end{array}$ \\
\hline $\begin{array}{l}\text { Grade of } \\
\text { pancreatic } \\
\text { trauma }\end{array}$ & & $\begin{array}{l}\text { Laparotomies } \\
=a+b+c\end{array}$ & $\begin{array}{l}\text { OM for } \\
\text { pancreas } \\
\pm \text { other } \\
\text { intra- } \\
\text { abdominal } \\
\text { organ (a) }\end{array}$ & $\begin{array}{l}\text { OM for } \\
\text { intra- } \\
\text { abdominal } \\
\text { organ } \\
\text { other than } \\
\text { pancreas } \\
\text { (b) }\end{array}$ & $\begin{array}{l}\text { OM for } \\
\text { unspecified } \\
\text { reason (c) }\end{array}$ & Total (\%) & \\
\hline $1 / I I$ & 13 & 6 & 2 & 3 & 1 & 19 (34.6) & 13 \\
\hline III & 1 & 9 & 6 & 0 & 3 & 10 (18.2) & 12 \\
\hline IV & 2 & 2 & 1 & 0 & 1 & $4(7.3)$ & 16 \\
\hline V & 0 & 1 & 0 & 1 & 0 & $1(1.8)$ & 17 \\
\hline NA & 12 & 9 & 2 & 4 & 3 & $21(38.2)$ & 12 \\
\hline Total & 28 & 27 & 11 & 8 & 8 & 55 & 13 \\
\hline
\end{tabular}

\section{Conservative management}

28 patients (28,50.9\%) with pancreatic trauma were managed conservatively. 13 patients $(13,23.6 \%)$ had grade I/II pancreatic injury, one patient had grade III injury and two patients had grade IV injury. Of the patients managed conservatively, six patients (20\%) died, two with grade I/II injury, one with grade IV injury and three who could not be assigned a grade. The median length of stay for patients managed conservatively was 13 days. 


\section{Operative Management}

27 patients (49.1\%) underwent surgical exploration in the form of laparotomies. 11 procedures were undertaken for pancreatic injury, which ranged from one pancreatic laceration repair for a grade I/II injury, nine distal pancreatectomies done for one grade I/II injures and six grade III. Grades of two other distal pancreatectomy were not available and one pancreaticoduodenectomy done for grade IV injury.

Of the six operated grade I/II patients, three patients were operated for right liver laceration, jejunal perforation and colonic transection. Two patients were operated for pancreatic injuries, one operated for pancreatic laceration where repair was performed with management of grade IV splenic injury, and the other was with pancreatic contusion in whom a distal pancreatectomy was done. All patients with grade III (9) pancreatic injury were operated on except the pediatric patient. Details of the other operated patient with grade IV pancreatic injury was not available. (Figure 2)

Two patients with grade IV injuries were conserved. One with no associated injuries, while the other with liver injuries and lesser sac hematoma, both whom were young adults. More details about the reason for the conservative management of these patients could not be inferred from the data. The only patient with grade $V$ injury in our study was operated for transection at D2 segment of duodenum, probably along with some surgery for pancreas, details of which are not available.

Of the patients managed operatively, seven patients died (28\%), one with grade I/II injury and one with grade IV injury and five could not be graded. The patient with grade I/II injury died due to head injury in one day, the patient had grade IV injury who died after 15 days of hospital stay, most likely due to pancreatic injury, as there were no other injuries and one patient with grade $V$ injury died due to pancreatico-duodenal injuries after 18 days of hospital stay. All operated patients with grade III and IV injury survived.

Out of 25 patients who were operated on, surgery lasted for 1-3 hours in 23 patients, $>4$ hours in one patient and data was not available for one patient. The median length of stay was 12 days (IQR 8 -27 days), for patients who survived as well as died.

\section{Discussion}

We found that conservative management was more common in low grade injuries compared with high-grade injuries, which were operated on. We also found that $82 \%$ of patients had at least one injury other than pancreas.

Out of 19 patients with grade I/II injuries in our study, 13 were managed conservatively, and six patients were managed operatively. The Eastern Association for the Surgery of Trauma (EAST) guidelines, Western Trauma Association (WTA) algorithm and World Society of Emergency Surgery (WSES) guidelines for management of pancreatic injuries recommends conservative management of AAST grade I and II (low-grade) blunt pancreatic injury(17-19). Operative management in low grade pancreatic injuries is usually done for associated injuries(4). Pancreatic injuries are often incidentally detected intraoperatively while a laparotomy is done for other injuries. At that time, surgical hemostasis and drainage is recommended. Resection is avoided due to delayed complications like formation of pseudocyst and fistulae. $(17,19)$ In our cohort, three patients were operated for associated injuries and two patients were operated due to pancreatic injuries. In our experience, intra-operatively, it may not be possible to detect a pancreatic ductal injury and sometimes a surgeon may go ahead with a distal pancreatectomy if there are major bruises over the pancreatic tail and clinical suspicion of pancreatic ductal injury in the tail even though a CT scan did not find it. 
Out of 10 patients with grade III injuries, nine were operated on and six underwent surgery for pancreatic injury. All six underwent distal pancreatectomy with or without splenectomy. Distal pancreatectomy is recommended for grade III injuries $(17,20)$. However, in select hemodynamically stable patients, with proximal pancreatic body injuries, conservative management with endoscopic and percutaneous interventions increases success of non-operative management (18). Distal injuries should undergo operative management in the form of distal pancreatectomy(18).

Only one patient of grade III injury was conserved, probably because he was a child with better chances of recovery with conservative management and hence lesser morbidity. In the pediatric population, there have been studies demonstrating success of non-operative management in management of high-grade pancreatic injuries (7). For pediatric pancreatic trauma, there exist no standard guidelines or recommendations for management $(21,22)$. A systematic review recommends conservative management of low grade pancreatic injuries (grade I-II). However, there is no consensus on the recommendation for high grade injury (grade III IV V)(21).

Of the four patients with grade IV injuries, two were operated and two were conserved. EAST guidelines recommend operative management of high-grade blunt pancreatic injury(17). WSES guidelines have similar recommendations for high grade pancreatic trauma; operative management in the form of debridement, over sewing the proximal pancreatic stump, distal drainage with pancreatico-jejunostomy and sometimes a staged pancreaticoduodenectomy. If a patient is hemodynamically stable, has no other associated injuries needing surgery, has availability of other conservative interventions at high resource centers, non-operative management can be tried (18). There are recent trends of conservative management even for high grade injuries as studies have failed to show a significant difference in mortality outcome with resection over conservative management, only a decrease in length of stay (23).

Of the 28 patients (50.9\%) managed conservatively, six patients $(20 \%)$ died. Out of these patients, two patients had grade I/II injuries and they mostly succumbed to other associated high-grade injuries. Out of the 27 patients (49.1\%) who underwent surgical exploration in the form of laparotomies. eight patients died $(30 \%)$. Mortality due to pancreatic trauma is difficult to ascertain because of multiple associated injuries in patients especially due to road traffic injuries leading to blunt multi-system trauma.

Pancreatic injury most commonly occurs with other associated injuries in as much as $90 \%$ of patients $(24,25)$. In our study 45 patients (82\%) had associated injuries. The liver, spleen, stomach, duodenum and colon are the most injured organs. A study noted associated injury to the liver (26\%), colon or small bowel (25\%), major vessels (25\%), duodenum (24\%), stomach (19\%), spleen (12\%) and kidney (10\%)(26) which is similar to our study where liver is the second most common injury in $31 \%$ patients and spleen in $24 \%$ patients, suggesting that larger solid organ and organs with close proximity to pancreas are more prone to injuries with pancreas. 19 (35\%) patients had thoracic injuries. Although thoracic injuries are not widely reported and only one study reported thoracic injuries in $53 \%$ patients with blunt trauma(27), in our study it was the most common associated injury. This finding could be due to the overwhelming predominance of blunt trauma in our study. Contrary to other studies with a high number of concomitant vascular injuries in other studies (2), our study had only 3 patients with vascular injury. This may be due to the high volume of low impact blunt trauma in our setup leading to less shear force needed for vascular injury.

\section{Limitations}

Firstly, data regarding the Magnetic Resonance Imaging (MRI), Endoscopic Retrograde Cholangiopancreatography (ERCP) and interventional radiology done in our patients were not available. Second, the profile and outcomes in 
pancreatic injury reported by us are from tertiary care university hospitals and cannot be generalized to smaller centers and to hospitals in the villages where the resources available are limited and variable.

\section{Conclusion}

Conservative management was as common as operative management in patients with pancreatic injuries. Most $(80 \%)$ grade III/IV underwent operative treatment. 45 patients (82\%) had associated injuries. Concomitant thoracic, hepatic and splenic injuries were most common.

\section{Abbreviations}

TITCO - Towards Improved Trauma Care Outcomes

KEM - King Edward Memorial Hospital

LTMGH - Lokmanya Tilak Municipal General Hospital

JPNATC - Jai Prakash Narayan Apex Trauma Centre

SSKM - Seth Sukhlal Karnani Memorial Hospital

ISS - Injury Severity Score

ICD - International Classification of Diseases

OIS - Organ Injury Scale

AAST - American Association for the Surgery of Trauma

CT - Computed Tomography

SBP - Systolic Blood Pressure

HR - Heart Rate

RR - Respiratory Rate

OM - Operative Management

FAST - Focused Assessment with Sonography for Trauma

EAST - Eastern Association for the Surgery of Trauma

WTA - Western Trauma Association

WSES - World Society of Emergency Surgery

MRI - Magnetic Resonance Imaging

ERCP - Endoscopic Retrograde Cholangiopancreatography 


\section{Declarations}

\section{Ethics Approval:}

The TITCO project was granted waivers of informed consent from all study centres. The study received approval from the institutional ethics committee of the four centres involved in the study. The ethics approval registration numbers were EC/NP-279/2013 RP-01/2013 from the All India Institute of Medical Sciences Ethics Committee, IEC/11/13 from the Lokmanya Tilak Municipal Medical College and Lokmanya Tilak Municipal General Hospital Institutional Ethics Committee, IEC/279 from the Institute of Post Graduate Medical Education and Research (IPGME\&R) Research Oversight Committee (Institutional Ethics Committee), and IEC(I)OUT/222/14 from the Seth GS Medical College and King Edward Memorial Hospital Institutional Ethics Committee.

\section{Availability of data and materials:}

This is a subgroup analysis of patients with pancreatic injury from a prospective trauma registry study named 'Towards Improved Trauma Care Outcomes' (TITCO) in India. [Roy N, Gerdin M, Ghosh S, et al (2016) 30-day inhospital trauma mortality in four urban university hospitals using an Indian Trauma Registry. World J Surg 40:12991307]. Data can be requested from the authors.

\section{Competing Interest.}

All authors declare that they have no competing interest to disclose.

\section{Funding.}

The TITCO funding agencies were the Swedish National Board of Health and Welfare and the Laerdal Foundation. The authors declare that these agencies had no influence on the conceptualization or findings of this study.

\section{Statement on Ethical Standard:}

All procedures performed were in accordance with the ethical standards of the institutional and national research committee and with the 1964 Helsinki Declaration and its later amendments.

\section{Consensus and Publication Statement:}

This is a subgroup analysis of patients with pancreatic injury from a prospective trauma registry study named 'Towards Improved Trauma Care Outcomes' (TITCO) in India. [Roy N, Gerdin M, Ghosh S, et al (2016) 30-day inhospital trauma mortality in four urban university hospitals using an Indian Trauma Registry. World J Surg 40:12991307]

This analysis and manuscript has not been published and is neither under consideration for publication elsewhere.

\section{Author Contributions.}


All authors contributed to the study equally. All authors have read and approved the final manuscript.

\section{Acknowledgment.}

Not applicable.

\section{References}

1. Costa G, Tierno SM, Tomassini F, Venturini L, Frezza B, Cancrini G, et al. The epidemiology and clinical evaluation of abdominal trauma. An analysis of a multidisciplinary trauma registry. Annali italiani di chirurgia. 2010;81(2):95-102.

2. Agarwal H, Gupta A, Kumar S. An overview of pancreatic trauma. Journal of Pancreatology. 2020 May;1.

3. Davenport M. Pancreatic trauma. In: Surgery of the Liver, Bile Ducts and Pancreas in Children, Third Edition [Internet]. CRC Press; 2017 [cited 2021 Mar 15]. p. 329-37. Available from:

https://www.ncbi.nlm.nih.gov/books/NBK459365/

4. Søreide K, Weiser TG, Parks RW. Clinical update on management of pancreatic trauma. Hpb [Internet]. 2018;20(12):1099-108. Available from: https://doi.org/10.1016/j.hpb.2018.05.009

5. Iacono C, Zicari M, Conci S, Valdegamberi A, de Angelis M, Pedrazzani C, et al. Management of pancreatic trauma: A pancreatic surgeon's point of view. Pancreatology [Internet]. 2016;16(3):302-8. Available from: http://dx.doi.org/10.1016/j.pan.2015.12.004

6. Schurink GWH, Bode PJ, van Luijt PA, van Vugt AB. The value of physical examination in the diagnosis of patients with blunt abdominal trauma: A retrospective study. Injury. 1997;28(4):261-5.

7. Kao LS, Bulger EM, Parks DL, Byrd GF, Jurkovich GJ. Predictors of Morbidity after Traumatic Pancreatic Injury. The Journal of Trauma: Injury, Infection, and Critical Care [Internet]. 2003 Nov [cited 2020 Dec 12];55(5):898905. Available from: http://journals.Iww.com/00005373-200311000-00016

8. Miller PR, Croce MA, Bee TK, Malhotra AK, Fabian TC. Associated injuries in blunt solid organ trauma: Implications for missed injury in nonoperative management. Journal of Trauma. 2002;53(2):238-44.

9. Shetty BN, Obalanarasimhaiah S, Nayankarahalli Swamigowda N, Kumar MM, Jena J. Management of pancreatic trauma in adult patients: a single centre experience. International Surgery Journal. 2020 Feb 26;7(3):705.

10. Ravindranath A, Srivastava A, Yachha SK, Poddar U, Sarma M sen, Saraswat VA, et al. Childhood pancreatic trauma: Clinical presentation, natural history and outcome. Pancreatology. 2020 Jan 1;20(1):68-73.

11. Garg RK, Mahajan JK. Blunt Trauma Pancreas in children: Is non-operative management appropriate for all grades? Pediatric Gastroenterology, Hepatology and Nutrition. 2017 Dec 22;20(4):252-8.

12. Gupta A, Kumar S, Yadav SK, Mishra B, Singhal M, Kumar A, et al. Magnitude, Severity, and Outcome of Traumatic Pancreatic Injury at a Level I Trauma Center in India. Indian Journal of Surgery. 2017 Dec 1;79(6):515-20.

13. Singh R, Mahajan A, Selhi J, Garg N, Chahal H, Bajwa M. Management and outcome of patients with pancreatic trauma. Nigerian Journal of Surgery [Internet]. 2017 [cited 2020 May 4];23(1):11. Available from: http://www.nigerianjsurg.com/text.asp?2017/23/1/11/199969

14. Yang WB, Li L, Chen H, Kong R, Wang G, Tan HT, et al. [The therapeutic experience of blunt pancreatic trauma]. Zhonghua wai ke za zhi [Chinese journal of surgery] [Internet]. 2019 [cited 2021 Mar 15];57(9):660-5. Available 
from: https://pubmed.ncbi.nlm.nih.gov/31474057/

15. Roy N, Gerdin M, Ghosh S, Gupta A, Kumar V, Khajanchi M, et al. 30-day in-hospital trauma mortality in four urban university hospitals using an Indian Trauma Registry. World Journal of Surgery [Internet]. 2016 Jun 1 [cited 2021 Mar 15];40(6):1299-307. Available from: https://pubmed.ncbi.nlm.nih.gov/26911610/

16. Moore EE, Cogbill TH, Malangoni MA, Jurkovich GJ, Champion HR, Gennarelli TA, et al. Organ injury scaling, II: Pancreas, duodenum, small bowel, colon, and rectum. Journal of Trauma - Injury, Infection and Critical Care. 1990;30(11):1427-9.

17. Ho VP, Patel NJ, Bokhari F, Madbak FG, Hambley JE, Yon JR, et al. Management of adult pancreatic injuries. Journal of Trauma and Acute Care Surgery [Internet]. 2017 Jan [cited 2021 May 1];82(1):185-99. Available from: https://journals.Iww.com/01586154-201701000-00025

18. Coccolini F, Kobayashi L, Kluger Y, Moore EE, Ansaloni L, Biffl W, et al. Duodeno-pancreatic and extrahepatic biliary tree trauma: WSES-AAST guidelines [Internet]. Vol. 14, World Journal of Emergency Surgery. BioMed Central Ltd.; 2019 [cited 2021 May 26]. Available from: /pmc/articles/PMC6907251/

19. Biffl WL, Moore EE, Croce M, Davis JW, Coimbra R, Karmy-Jones R, et al. Western trauma association critical decisions in Trauma: Management of pancreatic injuries. In: Journal of Trauma and Acute Care Surgery. 2013. p. 941-6.

20. Streith L, Silverberg J, Kirkpatrick AW, Morad Hameed S, Bathe OF, Ball CG. Optimal treatments for hepatopancreato-biliary trauma in severely injured patients: a narrative scoping review [Internet]. Vol. 63, Canadian Journal of Surgery. Canadian Medical Association; 2020 [cited 2021 May 4]. p. E431-4. Available from: /pmc/articles/PMC7608711/

21. Haugaard M v., Wettergren A, Hillings $\varnothing$ JG, Gluud C, Penninga L. Non-operative versus operative treatment for blunt pancreatic trauma in children [Internet]. Vol. 2014, Cochrane Database of Systematic Reviews. John Wiley and Sons Ltd; 2014 [cited 2021 May 1]. Available from: https://www.cochranelibrary.com/cdsr/doi/10.1002/14651858.CD009746.pub2/full

22. Englum BR, Gulack BC, Rice HE, Scarborough JE, Adibe OO. Management of blunt pancreatic trauma in children: Review of the National Trauma Data Bank. Journal of Pediatric Surgery [Internet]. 2016 Sep 1 [cited 2021 May 1];51(9):1526-31. Available from: /pmc/articles/PMC5142528/

23. Mohseni S, Holzmacher J, Sjolin G, Ahl R, Sarani B. Outcomes after resection versus non-resection management of penetrating grade III and IV pancreatic injury: A trauma quality improvement (TQIP) databank analysis. Injury. 2018 Jan 1;49(1):27-32.

24. Menahem B, Lim C, Lahat E, Salloum C, Osseis M, Lacaze L, et al. Conservative and surgical management of pancreatic trauma in adult patients. HepatoBiliary Surgery and Nutrition. 2016 Dec;5(6):470-7.

25. Bradley EL, Young PR, Chang MC, Allen JE, Baker CC, Meredith W, et al. Diagnosis and initial management of blunt pancreatic trauma: Guidelines from a multiinstitutional review. Annals of Surgery. 1998 Jun;227(6):861-9.

26. Chinnery GE, Krige JEJ, Kotze UK, Navsaria P, Nicol A. Surgical management and outcome of civilian gunshot injuries to the pancreas. British Journal of Surgery. 2012 Jan;99(SUPPL. 1):140-8.

27. Cogbill TH, Moore EE, Morris JA, Hoyt DB, Jurkovich GJ, Mucha P, et al. Distal pancreatectomy for trauma: A multicenter experience. Journal of Trauma - Injury, Infection and Critical Care. 1991;31(12):1600-6.

\section{Figures}




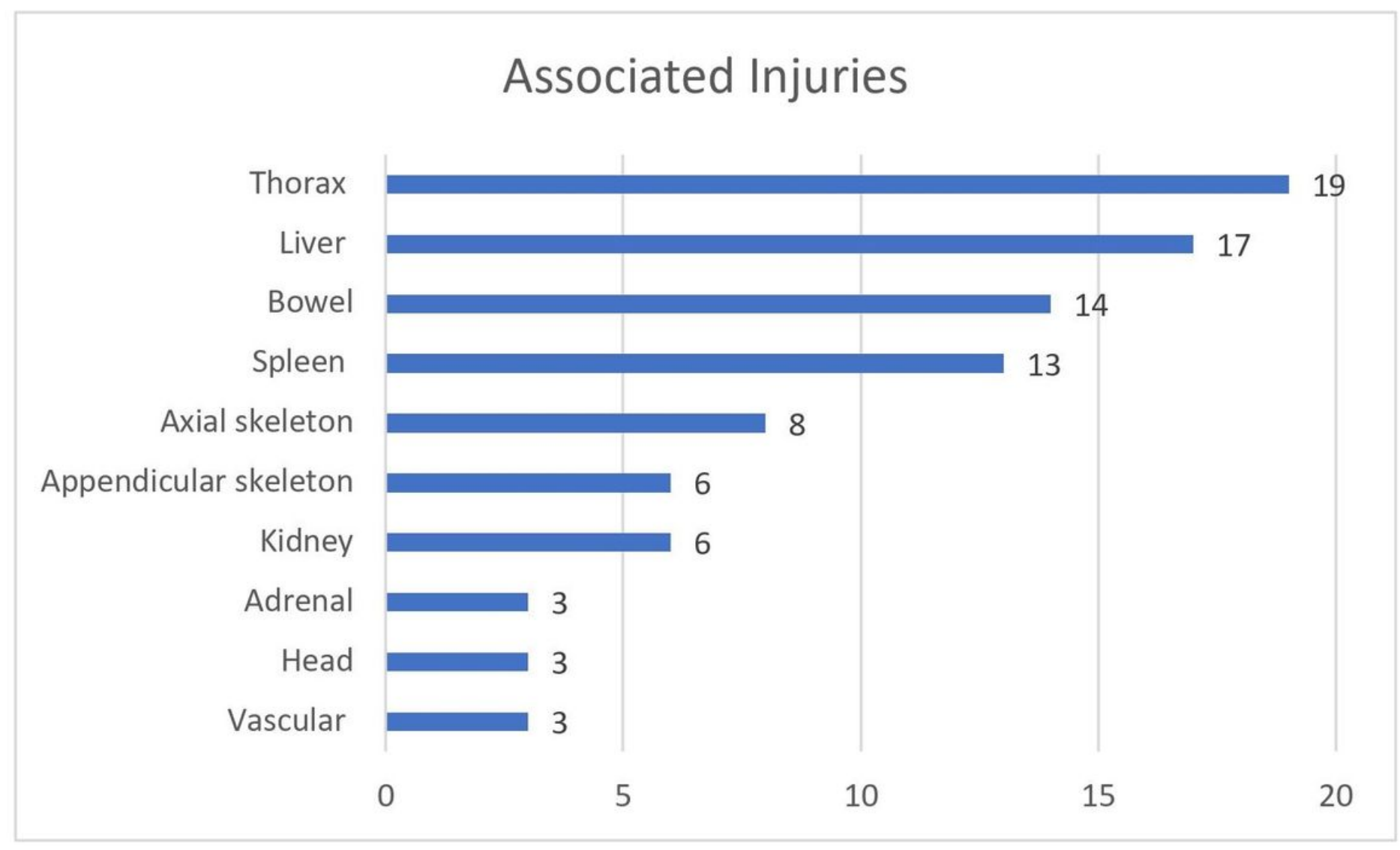

Figure 1

Associated other organ injuries with pancreatic trauma 


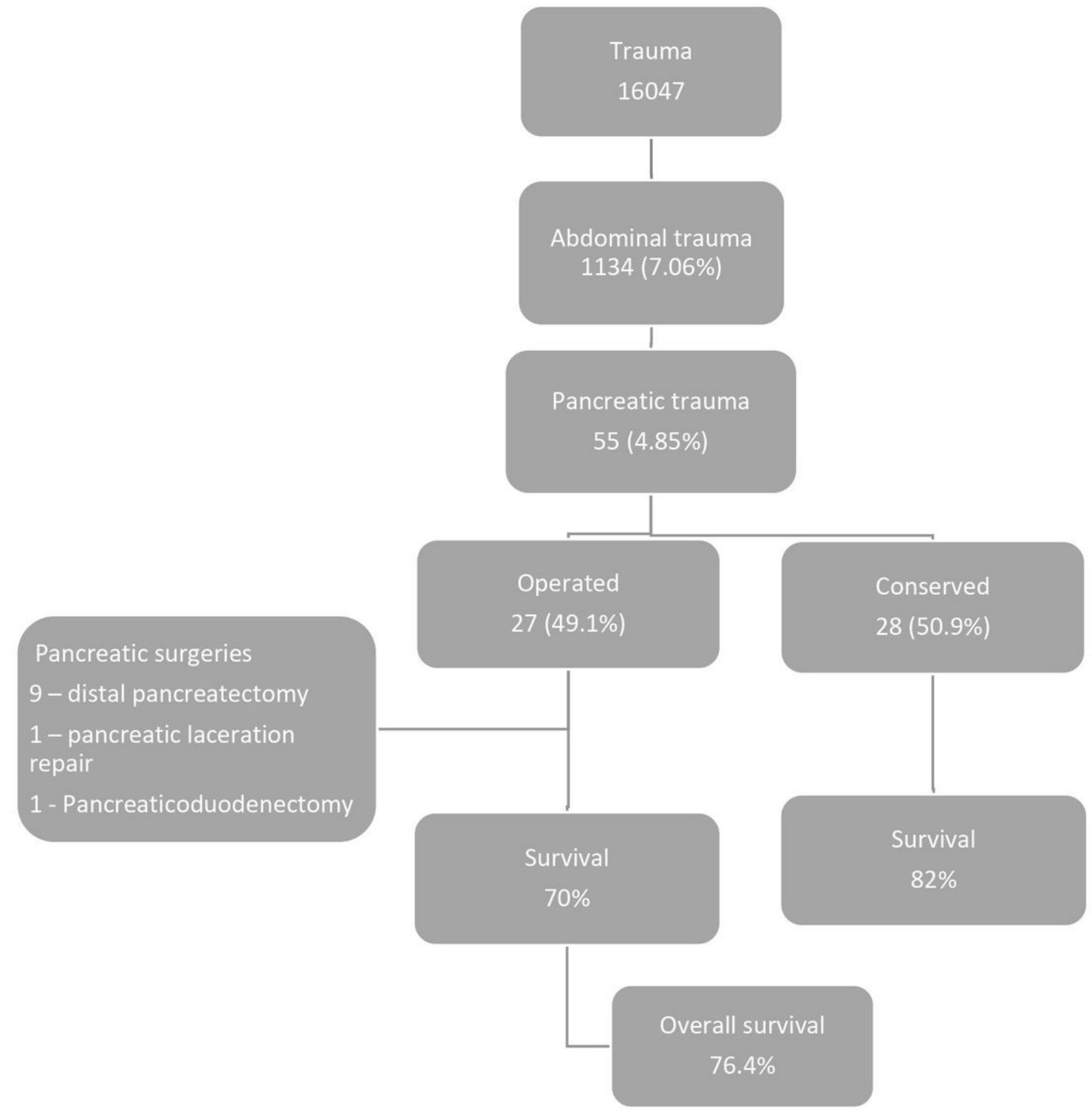

Figure 2

Patient flow 